\title{
RESULTS FROM LATARJET SURGERY FOR TREATING TRAUMATIC ANTERIOR SHOULDER INSTABILITY ASSOCIATED WITH BONE EROSION IN THE GLENOID CAVITY, AFTER MINIMUM FOLLOW-UP OF ONE YEAR
}

Roberto Yukio Ikemoto', Joel Murachovisky², Luis Gustavo Prata Nascimento², Rogério Serpone Bueno², Luiz Henrique Oliveira Almeida², Eric Strose ${ }^{2}$, Fábio Fernando Helmer ${ }^{3}$

\section{ABSTRACT}

Objective: Evaluate the results from the Latarjet procedure in patients with anterior recurrent dislocation of the shoulder who present bone loss of the glenoid cavity greater than $25 \%$. Methods: Twenty six male patients underwent the Latarjet procedure, The bone loss was evaluated by means of radiography using the Bernageau view and by means of CAT scan. The patients were evaluated with regard to range of motion, using the Rowe and UCLA scales, before and after the operation, and by radiographs to assess the presence of arthrosis, position and consolidation of the graft and positioning of the screws. Statistical analysis was used to assess whether there was any relationship between the number of episodes of dislocation and the presence of arthrosis, , and any relationship between arthrosis and limitations on lateral rotation. Differences in range of motion between the operated and unaffected sides and in the UCLA and Rowe scale. Results: The means for elevation and lateral rotation were statistically poorer on the operated side. The UCLA and Rowe scale showed that there was a statistically significant improvement in the clinical-functional results $(\mathrm{P}<0.001$ for both). There was a relationship between the number of episodes of dislocation and the presence of arthrosis, We also did not observe any correlation between limitations on lateral rotation and arthrosis. Conclusion: The Latarjet procedure is an efficient method for cases of severe erosion of the glenoid margin.

Keywords - Shoulder Dislocation/surgery; Joint Instability; Orthopedic Procedures; Erosion

\section{INTRODUCTION}

Capsulolabral repair, a technique described by Bankart $^{(1)}$ and popularized by Rowe et $a l^{(2)}$, is a procedure widely used in treating traumatic anterior instability of the shoulder. It presents good results ${ }^{(2-4)}$ except in cases in which there is bone erosion on the anteroinferior margin of the glenoid cavity ${ }^{(5-7)}$. In such situations, the chances of failure in Bankart repairs are close to $70 \%{ }^{(5)}$.

In 1990, Neer described a series of operated patients in which some individuals presented major erosion or wear on the anteroinferior margin of the glenoid cavity. It was recommended for these patients that they should undergo implantation of a graft from the coracoid process. However, this author did not define the percentage of compromising of the glenoid cavity from which use of a graft would be indicated, or the frequency of such lesions ${ }^{(8)}$.

Bigliani et $a l^{(9)}$ classified lesions of the anteroinferior rim of the glenoid cavity into three categories, according to the type and size of the

\footnotetext{
1 - Head of the Orthopedics Service, Hospital Ipiranga, and Shoulder and Elbow Group, ABC School of Medicine, São Paulo, SP, Brazil.

2 - Attending Physician in the Shoulder and Elbow Group, ABC School of Medicine, and Hospital Ipiranga, São Paulo, SP, Brazil.

3 - Trainee Physician in the Shoulder and Elbow Group, ABC School of Medicine, and Hospital Ipiranga, São Paulo, SP, Brazil.

Work performed in the ABC School of Medicine and Hospital Ipiranga.

Correspondence: Rua Monte Alegre 253/121, 09531-110 São Caetano do Sul, SP, Brazil. Email: rob.ike@hotmail.com

Work received for publication: October 27, 2009; accepted for publication: March 25, 2011.
}

The authors declare that there was no conflict of interest in conducting this work 
defect, and reported that erosion greater than $25 \%$ occurred in only $11 \%$ of a series of 200 patients.

According to Burkhart and De Beer ${ }^{(5)}$, the acceptable limit of bone deficiency in the anteroinferior glenoid for which capsulolabral repair would be possible was $25 \%$ of its diameter. For erosion greater than this, defined as an inverted pear-shaped glenoid ${ }^{(10)}$, there was a need to restore the glenoid cavity with a bone graft fixed at the defect site ${ }^{(5,11)}$.

According to Itoi et $a l^{(6)}$, bone defects of the glenoid cavity greater than $21 \%$ had the effect that the force required for shoulder dislocation to occur would be $50 \%$ lower than if such erosion had not been present. Application of a bone graft at the defect site would increase the stability and consequently the force needed for dislocation to occur.

The surgical techniques for filling bone defects in the anteroinferior region of the glenoid cavity use either a tricortical bone graft removed from the iliac crest ${ }^{(12)}$ or a fragment of the coracoid process, transferred together with the conjoined tendon ${ }^{(13,14)}$.

The advantage of the latter is explained by the "triple block" effect, which provides: 1) bone block; 2) tendon truss effect, in a combination that is under tension across the inferior portion of the subscapularis and capsule when the shoulder is in the abduction and lateral rotation position; and (3) capsulolabral tensioning, which occurs after suturing of the capsule to the coracoacromial ligament inserted in the bone graft ${ }^{(15)}$.

This study had the aim of retrospectively evaluating the clinical and functional results from patients who underwent Latarjet surgery to treat recurrent traumatic anterior unidirectional dislocation of the shoulder that was associated with bone defects greater than $25 \%$ in the anteroinferior margin of the glenoid cavity.

\section{METHODS}

Between November 2001 and July 2007, 29 patients underwent Latarjet surgery to treat recurrent traumatic anterior unidirectional dislocation of the shoulder that was associated with bone loss greater than $25 \%$ in the anteroinferior portion of the glenoid cavity. Of these, 26 patients returned for evaluations for this study. All of them were male, with a mean age of 28 years, and a range from 17 to 47 years. The mean length of the postoperative follow-up was 38 months, ranging from 12 to 80 months, with a minimum of one year. The number of episodes of dislocation that had occurred up to the time when the surgery was performed ranged from two to 100 , with a mean of 40 episodes. All the patients presented traumatic etiology for the first episode of dislocation.

To quantify the bone loss, simple radiographs in Bernageau view and computed axial tomography were performed on the shoulder before the operation. The Bernageau view was produced in comparison with the unaffected side, and the distances between the anterior and posterior margins of the glenoid cavity were measured. From this, the bone losses could be calculated. When there was 50\% loss of the glenoid in the lower quadrant, we took this to mean that there had been erosion greater than $21 \%$. The tomographic sections were produced in the axial plane, at intervals of three millimeters, and were also comparative. The Latarjet surgical procedure was indicated for patients whose examinations presented evidence of anteroinferior bone erosion of the glenoid cavity greater than 25\% (Figures 1 and 2).

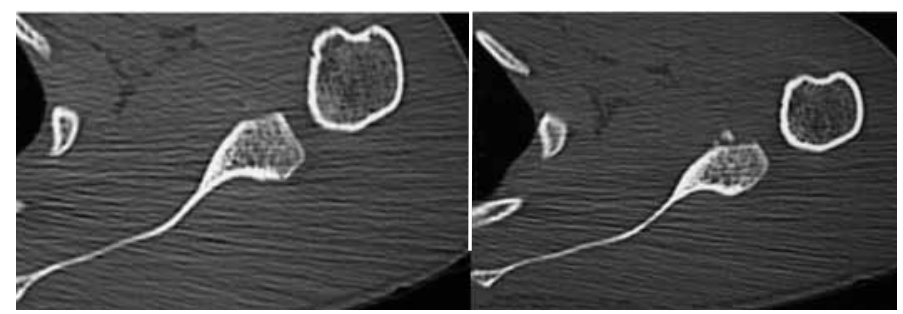

Figure 1 - Computed tomography on a shoulder in the axial plane, showing bone defect in the anteroinferior margin of the glenoid cavity.

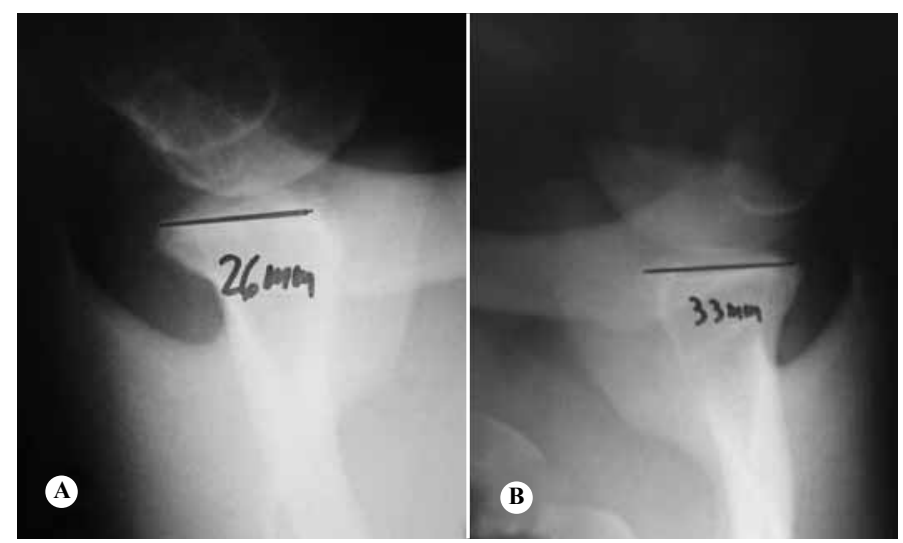

Figure 2 - Simple bilateral radiograph on a shoulder, in Bernageau view. A) Anteroinferior bone defect in the glenoid cavity; B) normal. 
The surgery was performed with the patient in semi-seated dorsal decubitus (in the deckchair position), under general anesthesia in association with brachial plexus block. The access used was deltopectoral, with recognition and lateral isolation of the cephalic vein, along with the deltoid muscle. The coracoid process was identified, and then the pectoralis minor was deinserted and the coracoacromial ligament was sectioned, while preserving one centimeter of its insertion in the coracoid process. Following this, osteotomy of the coracoid process was performed as proximally as possible. By palpating the coracoclavicular ligaments, we performed the osteotomy just before their insertion into the coracoid process, taking care not to damage them. The graft was obtained from the origin of the conjoined tendon and was prepared by means of scarification of its lower surface. Two openings were made using a 2.5 $\mathrm{mm}$ drill bit. The tendon of the subscapularis muscle was deinserted in an L-shape in 19 patients and was opened longitudinally, along the orientation of its fibers, in seven patients. Capsulotomy was performed vertically, to obtain the joint exposure needed for inspecting the joint. In the patients whose tendon of the subscapularis muscle had been deinserted in an inverted L-shape, one centimeter of the tendon was left at its insertion in the lesser tubercle. The tendon was then sectioned longitudinally along the direction of its fibers, from the interval of the rotators caudally as far as the lower third of the tendon. Capsulotomy was then performed and the Bankart lesion was repaired using three transosseous stitches. In the patients whose tendon of the subscapularis muscle had been opened longitudinally, only one portion of the capsule, together with the labrum, was excised. After identification of the bone defect in the anteroinferior portion of the glenoid cavity, it was scarified until a bleeding bone bed was obtained. The bone fragment from the coracoid process was fixed in the lower quadrant of the glenoid using two 3.5 mm spongy screws with partial threading, at around seven millimeters medially from the joint line, while attempting to position the lower screw at the five or seven o'clock position in the glenoid cavity, depending on whether it was a right or left shoulder. The portion of the coracoacromial ligament that remained inserted in the coracoid process was sutured to the capsule, and this procedure was performed with the shoulder at its maximum lateral rotation. The tendon of the subscapularis muscle was reinserted and the remaining layers were sutured. After the operation, the patients' operated arm was kept immobilized in a Velpeau sling, and the patients were instructed to perform flexion-extension exercises on the wrist and elbow. In the cases in which the tendon of the subscapularis muscle had been deinserted, the patient was instructed to perform passive lateral rotation of the shoulder as far as the neutral position, and assisted active rotation, for around four weeks. In the cases in which the tendon of the subscapularis muscle had been opened longitudinally, the patient was released to do full lateral rotation. The immobilization was subsequently removed and exercises to gain mobility were started in all planes, which progressed to muscle strengthening exercises. In cases of muscle tendon deinsertion, the strengthening started after four months, while in the other cases, it started as soon as the patient presented complete mobility.

The clinical evaluation conducted at least one year after the operation consisted of the following: bilateral measurement of shoulder range of motion (elevation, medial rotation, lateral rotation along the side of the body and lateral rotation at abduction of $90^{\circ}$ ) with the aim of comparing whether there was any limitation of mobility in relation to the non-operated side; anterior jerk test; bilateral test on medial shoulder rotation strength, with the aim of comparatively assessing (in relation to the unaffected side) whether there had been any diminution of secondary strength through the weakening of the subscapularis muscle; and also the liftoff and belly press tests ${ }^{(16-18)}$. We also performed a radiographic evaluation by means of radiographs in corrected AP view and apical oblique view ${ }^{(19)}$, in order to view the presence of signs of shoulder arthrosis. The degree of arthrosis was determined in accordance with the classification of Samilson and Prieto ${ }^{(20)}$. The Bernageau view was also used, to evaluate the degree of consolidation of the bone graft, the positioning of the screws and graft, and any signs of loosening of the synthesis material. The functional scales of Rowe et al(21) and UCLA ${ }^{(22)}$ were applied and their results were compared with the values obtained before the operation.

The statistical analysis on the results was performed using the SPSS software (Statistical Package for the Social Sciences), version 13.0, and the significance 
level was taken to be 5\%. The Kruskal-Wallis and Mann-Whitney tests were used to ascertain the relationship between the number of episodes of dislocation and the presence of arthrosis. Spearman's correlation was used to ascertain the relationship between the degree of arthrosis and the limitation on lateral rotation. The Wilcoxon signed rank test was used to compare the difference in range of motion between the operated and normal sides and between the pre and postoperative scores from the UCLA and Rowe scales.

\section{RESULTS}

The mean ranges of motion of the operated and unaffected sides, and their differences, are presented in Table 1.

Table 1 - Range of motion of the operated and contralateral limb.

\begin{tabular}{|c|c|c|c|c|c|c|}
\hline Movement & $\mathbf{n}$ & Mean & $\begin{array}{l}\text { Standard } \\
\text { deviation }\end{array}$ & Minimum & Maximum & $\begin{array}{c}\text { Significance } \\
\text { (p) }\end{array}$ \\
\hline $\operatorname{ELEV}(\mathrm{A})$ & 26 & 163.46 & 4.85 & 160.00 & 170.00 & \multirow{2}{*}{$<0.001$} \\
\hline ELEV (B) & 26 & 171.35 & 8.67 & 155.00 & 180.00 & \\
\hline $\operatorname{MR}(\mathrm{A})$ & 26 & 7.73 & 2.03 & T5 & T12 & \multirow{2}{*}{0.004} \\
\hline MR (B) & 26 & 6.35 & 0.98 & T5 & T8 & \\
\hline $\operatorname{LR}(A)$ & 26 & 50.19 & 14.03 & 30.00 & 80.00 & \multirow{2}{*}{$<0.001$} \\
\hline LR (B) & 26 & 71.92 & 10.96 & 50.00 & 90.00 & \\
\hline $\begin{array}{l}\text { LR abduction } \\
\text { (A) }\end{array}$ & 26 & 89.81 & 11.87 & 60.00 & 120.00 & \multirow{2}{*}{$<0.001$} \\
\hline $\begin{array}{l}\text { LR abduction } \\
\text { (B) }\end{array}$ & 26 & 112.31 & 12.10 & 80.00 & 130.00 & \\
\hline
\end{tabular}

Legend: (A) operated, (B) contralateral, ELEV - elevation, MR - medial rotation $\mathrm{LR}$ - lateral rotation.

According to the Rowe scores, all the patients were classified as poor before the operation. After the operation, 25 patients $(96 \%)$ were classified as excellent and one (4\%) as a good result. The mean score was 36 before and 93 after the operation $(p<$ $0.001)$. According to the UCLA score, eight patients (31\%) were classified as good, $12(46 \%)$ as fair and six $(23 \%)$ as poor before the operation. After the operation, $20(77 \%)$ were classified as excellent and six $(23 \%)$ as good. The mean score was 23 before and 34 after the operation $(\mathrm{p}<0.001)$.

There were no cases of recurrence of the dislocation, but the anterior jerk test remained positive in one patient. This patient was classified as good on the Rowe scale, but the result on the UCLA scale was considered to be excellent.

The medial shoulder rotation strength was graded as $\mathrm{V}$ in all the cases, both on the operated and on the contralateral side. None of the cases presented a positive belly press or liftoff test on the operated side.

Regarding postoperative complications, four patients presented signs of osteolysis on the screws, and two of these patients also had signs of pseudarthrosis in the graft (Figure 3). In two patients, fixation of the graft could not be achieved with two screws: one, because the graft broke during the operation; and the other, because of the short osteotomy of the coracoid (Figure 4). In four patients, it was observed that the screws were incorrectly positioned (Figure $5)$. In these cases, the attitude of the screws was not perpendicular to the glenoid because the graft was in a lower position.

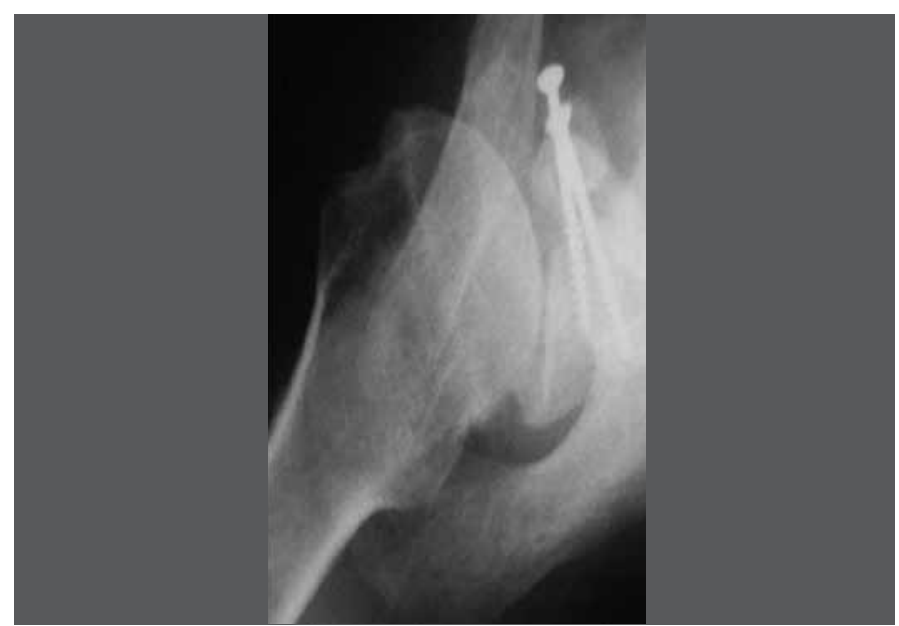

Figure 3 - Simple radiograph in Bernageau view showing nonconsolidation of bone graft.

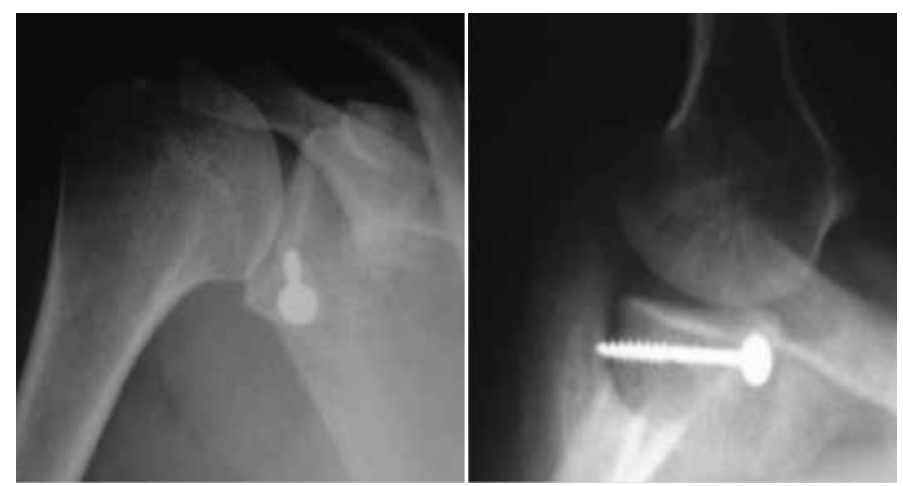

Figure 4 - Simple radiographs in corrected AP and Bernageau views showing short graft fixed with only one screw.

Eleven patients (42\%) did not present any radiographic evidence of arthrosis, while 15 did show evidence. Of the latter, 11 were classified as grade I $(42 \%)$, three as grade II $(12 \%)$ and one as grade III $(4 \%)$. We found that the episodes of dislocation were greater among the patients who presented arthrosis 


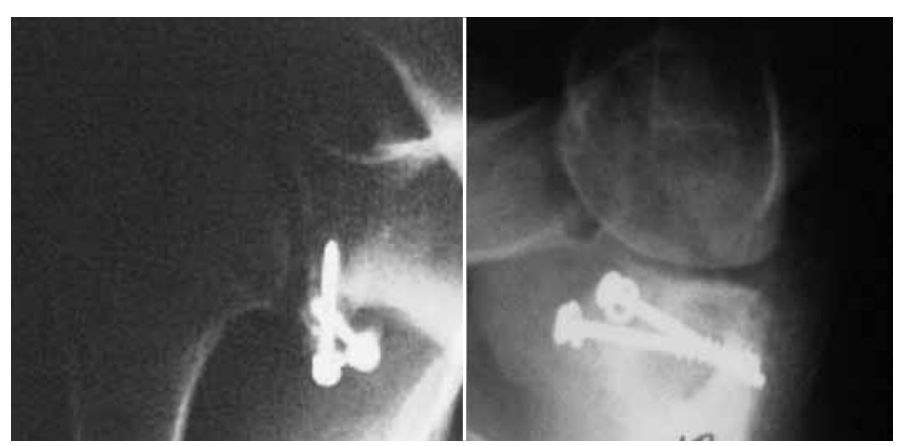

Figure 5 - Simple radiograph in corrected AP and Bernageau views showing incorrect positioning of the screws due to incorrect positioning of the graft (more inferiorly than it should have been).

of any degree (mild, moderate or severe) than among those without arthrosis $(p=0.008)$. There was no difference in the degree of arthrosis in relation to the number of previous dislocations $(p=0.069)$. There was also no relationship between development of arthrosis and limitation on lateral rotation along the side of the body $(\mathrm{p}=0.079)$ or with abduction of $90^{\circ}$ $(\mathrm{p}=0.078)$.

\section{DISCUSSION}

Latarjet surgery is characterized by its triple block. The action of the conjoined tendon in association with the graft from the coracoid process and the suturing of the coracoacromial ligament to the capsule make this surgery effective even when there is erosion of the anteroinferior rim of the glenoid cavity ${ }^{(5,15)}$.

In our sample, all the patients operated using the Latarjet technique presented erosion of the anteroinferior rim of the glenoid cavity greater than $25 \%$. Mologne et al ${ }^{(23)}$ found that $85 \%$ of the results from arthroscopic repair of dislocations were good when the lesions of the glenoid cavity were greater than $25 \%$, with a mean follow-up of 34 months. However, they emphasized that only the cases in which a bone fragment could be included in the repair had good evolution. Cases of erosion resulting from attrition presented a poor prognosis with this type of treatment. In a study on cadavers, Itoi et $a l^{(6)}$ found that the acceptable limit for anteroinferior erosion of the glenoid cavity, for which capsulolabral repair would be possible, was $21 \%$. Erosion greater than this would cause an overload on the capsule-ligament repair, which would then become insufficient. Burkhart and De Beer ${ }^{(5)}$ and Bigliani et $a l^{(9)}$ described erosion limits of $20 \%$ and $25 \%$, respectively. They recommended that, for cases of erosion greater than these limits, the anteroinferior surface of the glenoid cavity should be increased by means of bone graft fixation, given the high recurrence rate found when capsulolabral repair alone was performed ${ }^{(8)}$.

To determine whether Latarjet surgery would be needed among our patients, we used simple radiography and computed tomography examinations to observe whether bone erosion was present and, if so, to quantify its size. Like Edwards et $a l^{(24)}$, the radiographic view that we considered to be most important for demonstrating the bone erosion of the anteroinferior margin of the glenoid cavity was the view described by Bernageau et al ${ }^{(25)}$. Through this view, we were able to measure the distance between the posterior and anterior margins of the glenoid cavity and make correlations with the contralateral side, thus quantifying the percentage of erosion present ${ }^{(26)}$. Itoi et $a l^{(27)}$ demonstrated that through using the West Point view, it was possible to make an acceptable measurement of the percentage of erosion in the anteroinferior portion of the glenoid cavity. However, they commented on the difficulty of adequately measuring the quantity of bone loss and of reproducing the angle of projection of the radius, which ends up influencing the calculation of the magnitude of the erosion. We also did not find any study conducted on patients that provided that capability of reproduction of such calculations through this radiographic view.

With regard to computed tomography examinations, we analyzed the axial incidence on the lower sections to be able to estimate the quantity of bone erosion. As described by Itoi et $a l^{(27)}$, the erosion would be greater than $20 \%$ when the tomography examination indicated that the defect was greater than or equal to $50 \%$. In a study on the presence of anteroinferior bone erosion of the glenoid cavity, Griffith et al ${ }^{(28)}$ correlated the findings from the computed tomography examination with arthroscopy and found that the tomography examination presented sensitivity of $93 \%$ and specificity of $78 \%$ for identifying such lesions.

Ikemoto et $a l^{(29)}$ studied the glenoid cavity in anatomical specimens in an attempt to establish parameters between the upper, middle and lower segments of the glenoid cavity and thus make it possible to measure the magnitude of the erosion of the anteroinferior margin. They concluded that the 
measured values of the middle and lower segments were statistically equal and that the mean ratio between the upper and lower portions was 0.76 , and that this could be taken to be an index of normality in assessing the degree of erosion of the anteroinferior margin of the glenoid cavity.

Another method for quantifying the bone erosion that has been cited in the literature is through arthroscopy, by identifying the central point of the glenoid cavity (bare spot) and measuring the posterior and anterior halves using a guide graduated in millimeters. From this, the percentage of anterior bone defect present can be calculated ${ }^{(11)}$. However, Kralinger et $a l^{(30)}$ demonstrated that this bare spot was not always located at the center of the glenoid cavity, and thus could lead to error in determining the percentage erosion.

The mean number of episodes of dislocation among this sample, before undergoing the surgery, was 40 episodes. Only two patients suffered fewer than five episodes; the remainder of the patients had histories of many episodes, ranging from 13 to 100 , which was important in developing the erosion. We also believe that this excessive number of episodes led to development of arthrosis in a good proportion of these patients.

To determine the degree of arthropathy present, we used simple radiography examinations in corrected $\mathrm{AP}$ and apical oblique views, as recommended by Hovelius et $a l^{(31)}$. We found that $42 \%$ of the patients did not have any signs of arthropathy, $42 \%$ had mild arthropathy, $12 \%$ moderate and $4 \%$ severe. Other authors $^{(31-33)}$ found values ranging from $9 \%$ to $30 \%$ for arthropathy of moderate to severe degree after surgery to correct shoulder instability through bone block, with follow-up of up to 40 years.

We observed that the patients who developed arthrosis, independent of the degree, presented a greater number of dislocations prior to undergoing the surgery. This leads us to conclude that the main cause of the arthrosis was the excessive number of dislocations that these patients suffered. We did not find any directly proportional relationship between the number of dislocations prior to the surgery and the ascending degrees of arthrosis, although it needs to be emphasized that the samples of grades II and III were small, with low representativeness. In a prospective study involving 442 patients, Cameron et $a l^{(34)}$ concluded that the longer the time between dislocations and carrying out the surgery was, and the greater the patient's age was, the higher the chances of developing arthrosis would be ${ }^{(34)}$. In a study on the use of bone grafts for treating recurrent anterior shoulder dislocation among patients with bone deficiencies in the glenoid cavity, Doneaux et al ${ }^{(35)}$ found that $70 \%$ of the patients showed signs of arthrosis in the shoulder in the preoperative radiographic evaluation. According to Marx et $a l^{(36)}$, patients who presented an episode of dislocation presented a 10 to 20 times greater chance of developing moderate or severe arthropathy.

Over a mean follow-up of 15 years, Hovelius et $a l^{(31)}$ did not find any association between limited lateral rotation and development of arthrosis. They believed that the main factors that led to development of arthrosis were the number of previous dislocations and excessively lateral positioning of the bone graft. In our sample too, we did not observe any relationship between limitation on lateral rotation and arthrosis.

In our study, limitation of the mobility of the operated shoulder in relation to the contralateral shoulder occurred in all planes, with statistically significant differences. However, it was greatest for the movements of lateral rotation along the side of the body and in abduction of $90^{\circ}$, for which the mean losses were, respectively, $20^{\circ}$ and $22^{\circ}$. In an analysis on the postoperative results from 112 patients with two to five years of follow-up, Hovelius et al ${ }^{(31)}$ found similar values for the loss of lateral rotation along the side of the body and in abduction of $90^{\circ}$, with respective means of $19^{\circ}$ and $21^{\circ}$. Nonetheless, when these same patients were reevaluated after 15 years of follow-up, they presented a significant improvement, with respective means for losses of lateral rotation along the side of the body and in abduction of $90^{\circ}$ of $11^{\circ}$ and $12^{\circ(23)}$. Allain et $a l^{(32)}$ recommended that, to reduce the limitation on lateral rotation, the opening of the tendon of the subscapularis muscle should extend as medially as possible, in order to avoid an impact between the conjoined tendon and the belly of the subscapularis muscle during lateral rotation of the shoulder. Practitioners of sports activities that involve throwing actions are greatly affected by limitations on lateral rotation ${ }^{(29)}$, especially at abduction of $90^{\circ}$. In our sample, we did not have any cases of practitioners of throwing sports, and the limitations on movement did not imply difficulties in performing the patients' daily activities. Thus, these limitations did not compromise the clinical-functional results.

We did not observe any abnormalities of medial rotation strength on the operated side in comparison 
with the contralateral side, but the test was done by means of manual resistance imposed by the examiner, and perhaps this was the reason why we did not find any abnormality. We believe that this manner of evaluation was a weakness in our study, since it is known that changes can occur in the subscapularis muscle after its manipulation, especially fatty degeneration, as already described by other authors ${ }^{(37-40)}$. With the aid of a dynamometer, Marchaland et $a l^{(37)}$ evaluated the subscapularis muscle strength after Bristow-Latarjet surgery and found that there was a decrease in its strength of around $10 \%$, in comparison with the non-operated side, especially when the tendon was deinserted in an L-shape. They also observed that in the computed tomography examination, $25 \%$ of the patients presented some degree of fatty degeneration of the belly of the subscapularis muscle. In comparing deinsertion of the subscapularis in an L-shape with longitudinal opening, Maynou et $a l^{(40)}$ found that there was greater incidence of fatty degeneration in the cases subjected to deinsertion in an L shape, and recommended that access by means of the subscapularis muscle should be done longitudinally. In a study comparing the functional characteristics of the subscapularis muscle after surgery to correct shoulder instability using the open route and arthroscopy, Scheibel et al ${ }^{(38)}$ found abnormalities in the belly press and liftoff tests in $70 \%$ of the patients who underwent the open procedure, with abnormalities in the magnetic resonance examination suggestive of fatty degeneration of the belly of the subscapularis muscle. In $73 \%$ of our patients, the subscapularis muscle was deinserted in an L-shape and, although clinically the patients did not present any loss of medial rotation strength, we are aware that if such patients had been subjected to an evaluation using a dynamometer, they probably would have presented some degree of loss of strength. On the other hand, the belly press and liftoff tests ${ }^{(41)}$ were negative in all the cases.

We had few complications relating to the synthesis material and to consolidation of the bone graft, with two cases of pseudarthrosis, four cases of osteolysis of the screws and four cases of incorrect positioning of the screws. The latter was caused by lower positioning of the graft. In two cases of osteolysis, the patients evolved to pseudarthrosis and, in the other two, there was incorrect positioning of the screws. We agree with other authors that fixation of the graft with compression by means of two screws anchored in the posterior glenoid diminishes the chances of pseudarthrosis ${ }^{(27,32)}$. In two patients the graft fixation was by means of a single screw because of breakage of the graft and short osteotomy of the coracoid process. However, in both of these cases, graft consolidation occurred. We believe that these complications were mostly consequent to errors in the surgical technique and the surgeon's learning curve. However, these factors will not have influenced the final results of these patients, given that all these cases were classified as having satisfactory results and none of them presented any complaints. It is important to emphasize that in no case in this study was the graft from the coracoid process positioned laterally to the joint surface of the glenoid cavity, which diminished the chances of arthropathy and even of limitation of the lateral rotation. The ideal position would be four millimeters medially to the joint ${ }^{(31,32)}$.

Unlike the findings of other authors ${ }^{(27,42-44)}$, our patients showed excellent functional evolution according to the Rowe and UCLA scales. Only one of the patients did not present an excellent result on the Rowe scale, since the anterior jerk test remained positive in the final evaluation. Nevertheless, there was no recurrence of the dislocation. According to the UCLA scale, none of the cases were classified as fair or poor after the operation, in contrast with the 12 cases classified as fair and poor before the operation. It is worth noting that even among the patients who evolved with arthrosis or who had complications relating to breakage of the graft, inadequate positioning of the screws and pseudarthrosis, the final result was excellent. Over a mean follow-up of 14 years, Allain et al ${ }^{(32)}$ found an association between moderate or severe arthrosis and diminished functional results according to the Rowe scale.

The following were some of the limiting factors of our study: the short follow-up, given that it is quite likely that there will be a deterioration in the functional results among the patients with arthropathy; also, a minimum of one year of follow-up is not much for evaluating recurrences of dislocation, especially in this population of patients with anatomical abnormalities that greatly added difficulty to their treatment (even though the main length of follow-up was 38 months); and the fact that our sample consisted exclusively of male patients. 
The complications that occurred did not compromise the functional result, and we believe that the arthrosis did not occur because of limitation of the lateral rotation but, rather, because of the excessive number of dislocations.

\section{REFERENCES}

1. Bankart AS. The pathology and treatment of recurrent dislocation of the shoulder joint. Br J Surg.1938;26:23-9.

2. Rowe CR, Patel D, Southmayd WW. The Bankart procedure: a long-term endresult study. J Bone Joint Surg Am. 1978;60(1):1-16.

3. Gill TJ, Micheli LJ, Gebhard F, Binder C. Bankart repair for anterior instability of the shoulder. Long-term outcome. J Bone Joint Surg Am. 1997;79(6):850-7.

4. Kim SH, Ha KI, Cho YB, Ryu BD, Oh I. Arthroscopic anterior stabilization of the shoulder: two to six-year follow-up. J Bone Joint Surg Am. 2003;85(8):1511-8.

5. Burkhart SS, De Beer JF. Traumatic glenohumeral bone defects and their relationship to failure of arthroscopic Bankart repairs: significance of the inverted-pear glenoid and the humeral engaging Hill-Sachs lesion. Arthroscopy. 2000;16(7):677-94.

6. Itoi E, Lee SB, Berglund LJ, Berge LL, An KN. The effect of a glenoid defect on anteroinferior stability of the shoulder after Bankart repair: a cadaveric study. $\mathrm{J}$ Bone Joint Surg Am. 2000;82(1):35-46.

7. Lippitt SB, Vanderhooft JE, Harris SL, Sidles JA, Harryman DT 2nd, Matsen FA 3rd. Glenohumeral stability from concavity-compression: a quantitative analysis. J Shoulder Elbow Surg. 1993;2(1):27-35.

8. Neer CS. Shoulder reconstruction. Philadelphia: Saunders; 1990.

9. Bigliani LU, Newton PM, Steinmann SP, Connor PM, Mcllveen SJ. Glenoid rim lesions associated with recurrent anterior dislocation of the shoulder. Am J Sports Med. 1998;26(1):41-5.

10. Lo IK, Parten PM, Burkhart SS. The inverted pear glenoid: an indicator of significant glenoid bone loss. Arthroscopy. 2004;20(2):169-74.

11. Burkhart SS, Debeer JF, Tehrany AM, Parten PM. Quantifying glenoid bone loss arthroscopically in shoulder instability. Arthroscopy. 2002;18(5):488-91.

12. Churchill RS, Moskal MJ, Lippitt SB. Extracapsular anatomically contoured anterior glenoid bone grafting for complex glenohumeral instability. Techn Shoulder Elbow Surg. 2001;2(3):210-8.

13. Helfet AJ. Coracoid transplantation for recurring dislocation of the shoulder. $\mathrm{J}$ Bone Joint Surg Br. 1958;40(2):198-202.

14. Latarjet M. [Technic of coracoid preglenoid arthroereisis in the treatment of recurrent dislocation of the shoulder]. Lyon Chir. 1958;54(4):604-7.

15. Patte D, Bernageau J, Bancel P. The anteroinferior vulnerable point of the glenoid rim. In: Bateman JE, Wesch RP, editors. Surgery of the shoulder. New York: Marcel Dekker; 1985. p. 94-9.

16. Miller LS, Hazrati Y, Klepps S, Chiang A and Flatow EL. Loss of subscapularis functions after total shoulder replacement: A seldom recognized problem. J Shoulder Elbow Surg. 2003;12(1):29-34.

17. Scheibel M, Hambermeyer P. Subscapularis dysfunction following anterior surgical approaches to the shoulder.. J Shoulder Elbow Surg.2008;17(4):671-83.

18. Qureshi S, Hsiao A, Klung AR, Lee E, Braman J, Flatow EL. Subscapularis function after total shoulder replacement:Results with lesser tuberosity osteotomy. J Shoulder Elbow Surg.2008;17(1):68-72.

19. Garth WP Jr, Slappey CE, Ochs CW. Roentgenographic demonstration of instability of the shoulder: the apical oblique projection. A technical note. J Bone Joint Surg Am. 1984;66(9):1450-3.

20. Samilson RL, Prieto V. Dislocation arthropathy of the shoulder. J Bone Joint Surg Am. 1983;65(4):456-60.

21. Rowe CR, Patel D, Southmayd WW. The Bankart procedure: a long-term endresult study. J Bone Joint Surg Am. 1978;60(1):1-16.

22. Amstutz HC, Sew Hoy AL, Clarke IC. UCLA anatomic total shoulder arthroplasty. Clin Orthop Relat Res. 1981;(155):7-20.

23. Mologne TS, Provencher MT, Menzel KA, Vachon TA, Dewing CB. Arthroscopic stabilization in patients with an inverted pear glenoid: results in patients with bone loss of the anterior glenoid. Am J Sports Med. 2007;35(8):1276-83.

24. Edwards TB, Boulahia A, Walch G. Radiographic analysis of bone defects in chronic anterior shoulder instability. Arthroscopy. 2003;19(7):732-9.

\section{CONCLUSION}

The Latarjet surgical procedure was shown to be an efficient method for treating traumatic shoulder instability that presented bone erosion in the glenoid cavity. It provided joint stabilization and patient satisfaction over a mean follow-up period of 38 months.

25. Bernageau J, Patte D, Debeyre J, Ferrane J. [Value of the glenoid profil in recurrent luxations of the shoulder]. Rev Chir Orthop Reparatrice Appar Mot. 1976;62(2 Suppl):142-7.

26. Murachovsky J. Comunicação pessoal. In: $12^{\circ}$ Congresso de Ortopedia e Traumatologia do Estado de São Paulo, Campinas, SP, 2008.

27. Itoi E, Lee SB, Amrami KK, Wenger DE, An KN. Quantitative assessment of classic anteroinferior bony Bankart lesions by radiography and computed tomography. Am J Sports Med. 2003;31(1):112-8.

28. Griffith JF, Yung PS, Antonio GE, Tsang PH, Ahuja AT, Chan KM. CT compared with arthroscopy in quantifying glenoid bone loss. AJR Am J Roentgenol. 2007;189(6):1490-3.

29. Ikemoto RY, Checchia SL, Fujiki EN, Murachovsky J, Nascimento LGP. Análise das Mensurações da Cavidade Glenoidal em Peças Anatômicas. Rev Bras Ortop. 2005;40(11/12):663-71.

30. Kralinger F, Aigner F, Longato S, Rieger M, Wambacher M. Is the bare spot a consistent landmark for shoulder arthroscopy? A study of 20 embalmed glenoids with 3-dimensional computed tomographic reconstruction. Arthroscopy. 2006;22(4):428-32.

31. Hovelius L, Sandström B, Saebö M. One hundred eighteen Bristow-Latarjet repairs for recurrent anterior dislocation of the shoulder prospectively followed for fifteen years: study II-the evolution of dislocation arthropathy. J Shoulder Elbow Surg. 2006;15(3):279-89.

32. Allain J, Goutallier D, Glorion C. Long-term results of the Latarjet procedure for the treatment of anterior instability of the shoulder. J Bone Joint Surg Am. 1998;80(6):841-52.

33. Singer GC, Kirkland PM, Emery RJ. Coracoid transposition for recurrent anterior instability of the shoulder. A 20-year follow-up study. J Bone Joint Surg Br. 1995;77(1):73-6.

34. Cameron ML, Kocher MS, Briggs KK, Horan MP, Hawkins RJ. The prevalence of glenohumeral osteoarthrosis in unstable shoulders. Am J Sports Med. 2003;31(1):53-5.

35. Doneaux PS, Miyazaki AN, Lemos PEG, Souza AS, Checchia SL. Tratamento da luxação recidivante anterior do ombro: uso de enxerto ósseo na deficiência da glenóide. Rev Bras Ortop. 1997;32(9):675-82.

36. Marx RG, McCarty EC, Montemurno TD, Altchek DW, Craig EV, Warren RF. Development of arthrosis following dislocation of the shoulder: a case-control study. J Shoulder Elbow Surg. 2002;11(1):1-5.

37. Marchaland JP, Bures C, Versier G, Danguy des Desérts M, Rigal S. L'abord du subscapularis dans les butées coracoïdiennes. Étude rétrospective de 70 cas. Sci Sports. 2003;18:86-92.

38. Scheibel M, Nikulka C, Dick A, Schroeder RJ, Popp AG, Haas NP. Structural integrity and clinical function of the subscapularis musculotendinous unit after arthroscopic and open shoulder stabilization. Am J Sports Med. 2007;35(7):1153-61.

39. Greis PE, Dean M, Hawkins RJ. Subscapularis tendon disruption after Bankart reconstruction for anterior instability. J Shoulder Elbow Surg. 1996;5(3):219-22.

40. Maynou C, Cassagnaud X, Mestdagh H. Function of subscapularis after surgical treatment for recurrent instability of the shoulder using a bone-block procedure. J Bone Joint Surg Br. 2005;87(8):1096-101.

41. Tokish JM, Decker JM, Ellis BH, Torry RM, Hawkins JR. The belly press test for the physical examination of the subscapularis muscle:electromyographic validation and comparison to the lift-off test. J Shoulder Elbow Surg.2003;12(5):427-30.

42. Ferlic DC, DiGiovine NM. A long-term retrospective study of the modified Bristow procedure. Am J Sports Med. 1988;16(5):469-74.

43. Young DC, Rockwood CA Jr. Complications of a failed Bristow procedure and their management. J Bone Joint Surg Am. 1991;73(7):969-81.

44. Torg JS, Balduini FC, Bonci C, Lehman RC, Gregg JR, Esterhai JL, Hensal FJ. A modified Bristow-Helfet-May procedure for recurrent dislocation and subluxation of the shoulder. Report of two hundred and twelve cases. J Bone Joint Surg Am. 1987;69(6):904-13. 